\title{
SUSTAINABLE DECISION-MAKING MODEL BASED ON ANALYTICAL HIERARCHY PROCESS AND SWOT ANALYSIS: “S-AHP” MODEL
}

\author{
Fabio De Felice \\ University of Cassino and Southern Lazio \\ Department of Civil and Mechanical Engineering \\ Cassino (FR), ITALY \\ E-mail: defelice@unicas.it \\ Antonella Petrillo* \\ University of Cassino and Southern Lazio \\ Department of Civil and Mechanical Engineering \\ Cassino (FR), ITALY \\ E-mail: a.petrillo@unicas.it \\ Claudio Autorino \\ University of Naples "Parthenope" \\ Department for Technology \\ Naples (NA), ITALY \\ E-mail: claudio.autorino@uniparthenope.it \\ Armando Carlomusto \\ University of Cassino and Southern Lazio \\ Department of Civil and Mechanical Engineering \\ Cassino (FR), ITALY \\ E-mail: a.carlomusto@unicas.it
}

\begin{abstract}
Electrical and Electronic Equipment (EEE) is developing fast and spreading over every part of modern life. EEE include different substances that may cause serious damage to the environment and have adverse effects on human health so it is essential to manage the waste (WEEE) resulting from EEE properly. In the present study a systematic and strategic multi criteria method based on AHP and SWOT Analysis is proposed in order to identify a decision making model to improve the environmental sustainability of WEEE. In detail, the aim of the proposed model is to identify the critical factors in order to measure the "degree" of environmental sustainability of WEEE using a multicriteria model. The study is based on the consideration that for the improvement of the management of WEEE is essential to ensure the minimum efficiency levels. These levels can be evaluated from different points of view, but it is essential to involve all actors and stakeholders.
\end{abstract}

Keywords: AHP, WEEE, SWOT, Decision Model

\section{Introduction}

Waste Electrical and Electronic Equipment (WEEE) or e-waste, is one of the fastest growing advanced type of solid waste streams in the urban environment worldwide (Nnorom et al., 2008). Guaranteeing sustainable innovation - defined as the shift of sustainable technologies, products and services to the market - is forcing a new market creation concept and consequently, innovative common methodological

\footnotetext{
${ }^{*}$ Corresponding author
} 
approaches have to be introduced. Thus, WEEE management usually involves a complex decision process. Complex decisions must be considered from different points of views by a common approach. Defining the sustainability level of a process is usually a complex process as it involves economic, social, technological, environmental, ethical, and other kinds of controlling influences (De Felice and Petrillo, 2012). There is no better way to approach a complex problem than to structure all the important key influences affecting every important alternative course of action that we think of. Given a valid and comprehensive structure, the accuracy of measurement is the next critical requirement to ensure that the best decision con be identified (Silvestri et al., 2012). There is no universal and perfect approach for strategic sustainable planning in the WEEE field, thus in this study the strengths, weaknesses, opportunities, and threats based on SWOT approach integrated with AHP is used in order to assess the effect of environmental, economic, and social factors relating to a WEEE management. We called the new methodology S-AHP. Definitively, in the present paper, we attempt to propose a novel integrated model to identify the critical factors in order to measure the "degree" of environmental sustainability of WEEE using a multicriteria model based on S-AHP. The integrated model proposed by us would help to strengthen the "processing" part of the functional elements employed for proficient WEEE management. The S-AHP approach allows to define proper decision process in a hierarchical structure of factors, evaluate factors in pairs, and quantify the relative importance of each factor to the adoption decision (Ostrega, De Felice and Petrillo, 2011). The research methodology used consists mainly of four section. In the first section, the analysis of WEEE management is introduced by referring to information collected from literature review and regulations. In the second section the methodological approach and the integrated model S-AHP is presented. In the third section, a real case study based on S-AHP method (strengths, weaknesses, opportunities and threats of WEEE management) is performed based on the research developed and through analyzing information obtained from a series of focus group meetings. Finally in the fourth section results and conclusions are analyzed based on the principle of "maximize strengths and opportunities", transforming weaknesses to strengths, and minimizing threats.

\section{Preliminary analysis}

In European Union (EU), total amount of e-waste generation ranges from 5-7 million tons per annum or about 14-15 kg per capita and is expected to grow at the rate of 3-5\% per year. Currently, e-waste is the fastest growing component of the municipal solid waste stream for several reasons: from the quick diffusion of ICT tools to the rapid obsolescence of technological products in developed countries as people are upgrading their mobile phones, computers, televisions, audio equipment and printers more frequently than ever before (UNEP, 2007; UNEP 2009). The exponential growing of electronic products in our society is mainly contributing to increase this waste stream which is characterized by a high environmental impacts mainly due to the presence of both several hazardous substances and valuable recoverable materials (i.e. rare earth materials). The physical composition of e-waste is very diverse and contains over 1000 different substances, which falls under organic and inorganic fractions (cadmium, chromium, mercury, arsenic, selenium and precious metals like silver, gold, copper and platinum, etc.). Overview indicates that manufacturing of mobile phones and personal computers consumes $3 \%$ of gold and silver mined worldwide each year; $13 \%$ of the palladium and 15\% of cobalt (Bath et al., 2012).

Developing countries are also in the challenging phase as they are already facing the continuum of hazardous e-waste mountains. In the last two decades, there has been an increase in the number of environmental policies and legislations focusing on the product development process with a view to reducing the environmental impacts resulting from the products; throughout their entire lifecycle-from product design, manufacture, through to consumption and eventual end-of-life (EoL) management.

In particular, the European Union has imposed several important directives in the past decade. One of the most important directive in the field of waste management is the Directive on Waste Electronics and Electronic Equipment (WEEE). The WEEE directive introduces the concept of producer responsibility for the recycling and disposal of products at the end of the useful life. The implications of this directive have enormous impact on the product life cycle and how it is defined. They will encourage design for 
disassembly and alternatives to hazardous substances. To address the requirement of these Directives, companies in Europe have made significant innovations to eliminate or move toward zero material waste in the products' life cycle (Kumar et al., 2005). WEEE in general comprises wide categories of old or used appliances from small equipment (e.g. mobile phones, printers, computers, etc.) to large household appliances (e.g. refrigerators, freezers, mobiles phones, etc.) which require a safety and effective End-OfLife (EOL) management. In order to improve the management of WEEE we have developed a multi criteria model based on AHP to define a correct classification of WEEE. The proposed approach is useful to monitor their performance and to assess the priority of possible interventions to be taken, in order to increase the sustainability of the integrated system. The idea is to develop a multi-criteria decisionmaking model to assess the degree of environmental sustainability of WEEE.

\section{Literature review and methodological approach: The integrated model "S-AHP"}

SWOT is an acronym for strengths, weaknesses, opportunities and threats. Every program, project, development and management plan has its strengths and weaknesses, opportunities and threats. In the present work, SWOT analysis is applied to develop action plans for successful implementation for WEEE management. SWOT is a tool designed to be used in the preliminary stages of decision-making on the one hand and as a precursor to strategic management planning on the other (Srivastava et al., 2005). In the SWOT analysis, available resources and their potential utilization are studied from the viewpoints of economic, ecological and social sustainability. Each aspect of the information must be sound so that the best alternatives can be selected. Thus, SWOT is used for analyzing internal and external environments in order to attain a systematic approach and support for a decisive situation. If used correctly, it can provide a good basis for successful strategy formulation (Schmoldt, Peterson, 2000). The use of this method gives rise to some important advantages and disadvantages. The advantages, for instance, may include the idea that this method is very simple and everybody can use it without having advanced knowledge or external technical support. The disadvantages refer to a variety of shortcomings regarding this method such as its simplistic, static and subjective character. Then one of the main limitations of this approach is that the importance of each factor in decision-making cannot be measured quantitatively. As such it is difficult to assess which factors influences the strategic decision most (Pesonen et al., 2000). If used in combination with Analytic Hierarchy Process, SWOT approach can provide a quantitative measure of importance of each factor on decision-making (Saaty and Vargas, 2001; Ananda and Herath, 2003). In literature other authors proposed the use of AHP in the SWOT analysis. Examples in literature was proposed by Kurttila et al., 2000; Kajanus et al., 2004; Shrestha et al. 2004; Shinno et al., 2006; Wickramasinghe and Takano, 2010; Osuna and Aranda, 2007. In the previous works AHP was used to measure the relative importance weightings of the individual SWOT factors. Unlike the previous approaches, in our work AHP is used not only to weight SWOT factors but also to quantify intangible factors. In particular with:

- SWOT analysis we identified the strengths, weaknesses, opportunities, and threats that an organization faces. The strengths and weaknesses are identified by an internal environment appraisal, while the opportunities and threats are identified by an external environment appraisal;

- AHP enables decision-makers to quantify intangible factors.

In our opinion the integrated S-AHP approach is preferred as the intensities of strengths, weaknesses, opportunities, and threats can be quantified, and therefore can lead to a more realistic and effective decision than stand-alone SWOT or AHP.

In Figure 1 research methodological approach is shown. 


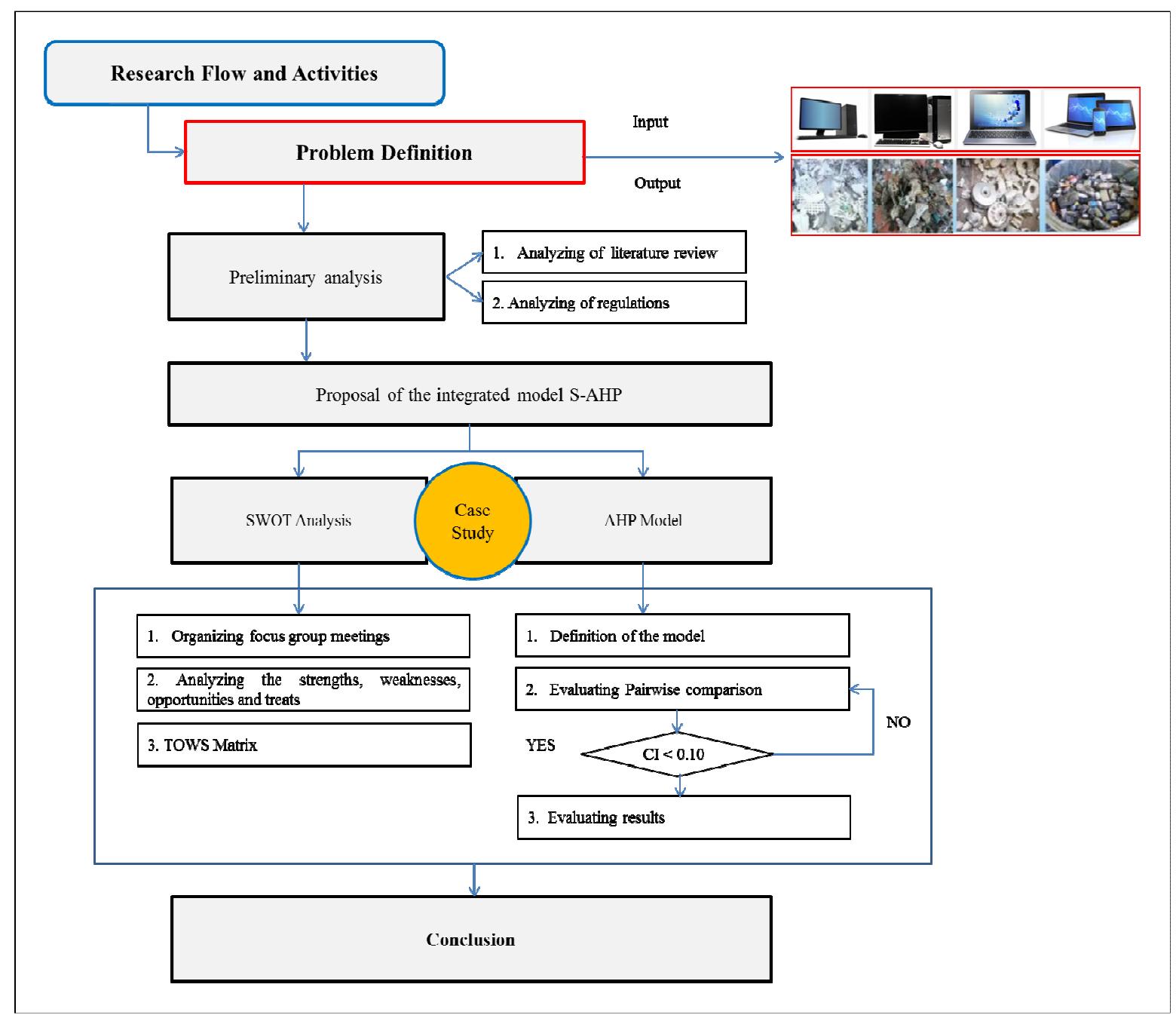

Figure 1. Methodological Approach.

\section{Case study description: Laptop}

One of the crucial elements in measuring the effectiveness of sustainability is to obtain consistent results according to common standards. In fact, the WEEE management depends on several factors. This implies that it is critical to elicit information from research and extension service.

\subsection{Organizing focus group meetings}

For implementing the proposed S-ANP approach, we selected ten participants and categorized them in two groups: Academic Expert (AE) and Governmental Expert (GE). Identification and classification of critical decision factors was accomplished using literature review and focus group discussions. From this point of view we constructed our model considering the EPEAT (Electronic Product Environmental Assessment Tool) standard. EPEAT is an US nonprofit organization which has defined a comprehensive environmental rating that helps identify greener computers and other electronic equipment. This is a rating system that can be used to compare the environmental performance of desktop and laptop computers and monitor and other electronic equipment.

In Table 1 is shown the list of EPEAT Parameters. 
Table 1.EPEAT parameters.

\begin{tabular}{|c|c|c|}
\hline Symbol & Classification & Description \\
\hline C.1 & EPEAT & Reduction/elimination of environmentally sensitive materials \\
\hline C1.1 & EPEAT & Compliance with provisions of European RoHS Directive upon its effective date \\
\hline $\mathrm{C} 1.2$ & EPEAT & Reporting on amount of mercury used in light sources (mg) \\
\hline $\mathrm{C} 1.3$ & EPEAT & $\begin{array}{l}\text { Elimination of intentionally added SCCP flame retardants and plasticizers in certain } \\
\text { applications }\end{array}$ \\
\hline C.2 & EPEAT & Materials selection \\
\hline $\mathrm{C} 2.1$ & EPEAT & Declaration of postconsumer recycled plastic content (\%) \\
\hline $\mathrm{C} 2.2$ & EPEAT & Declaration of renewable/bio-based plastic materials content (\%) \\
\hline $\mathrm{C} 2.3$ & EPEAT & Declaration of product weight (lbs) \\
\hline C.3 & EPEAT & Design for end of life \\
\hline C3.1 & EPEAT & Identification of materials with special handling needs \\
\hline $\mathrm{C} 3.2$ & EPEAT & Elimination of paints or coatings that are not compatible with recycling or reuse \\
\hline $\mathrm{C} 3.3$ & EPEAT & Easy disassembly of external enclosure \\
\hline $\mathrm{C} 3.4$ & EPEAT & Marking of plastic components \\
\hline $\mathrm{C} 3.5$ & EPEAT & Identification and removal of components containing hazardous materials \\
\hline C3.6 & EPEAT & Minimum 65 percent reusable/recyclable \\
\hline C.4 & EPEAT & Product longevity/life cycle extension \\
\hline C4.1 & EPEAT & Availability of additional three year warranty or service agreement \\
\hline $\mathrm{C} 4.2$ & EPEAT & Upgradeable with common tools \\
\hline C.5 & EPEAT & Energy conservation \\
\hline C5.1 & EPEAT & ENERGY STAR® \\
\hline C.6 & EPEAT & End of life management \\
\hline C6.1 & EPEAT & Provision of product take-back service \\
\hline C6.2 & EPEAT & Provision of rechargeable battery take-back service \\
\hline C.7 & EPEAT & Corporate performance \\
\hline C7.1 & EPEAT & Demonstration of corporate environmental policy consistent with ISO 14001 \\
\hline $\mathrm{C} 7.2$ & EPEAT & $\begin{array}{l}\text { Self-certified environmental management system for design and manufacturing } \\
\text { organizations }\end{array}$ \\
\hline $\mathrm{C} 7.3$ & EPEAT & Corporate report consistent with Performance Track or GRI \\
\hline C.8 & EPEAT & Packaging \\
\hline C8.1 & EPEAT & Reduction/elimination of intentionally added toxics in packaging \\
\hline $\mathrm{C} 8.2$ & EPEAT & Separable packing materials \\
\hline $\mathrm{C} 8.3$ & EPEAT & Declaration of recycled content in packaging \\
\hline
\end{tabular}

\subsection{Analyzing the strengths, weaknesses, opportunities and treats}

After preparing the preliminary list of decision factors, we defined 12 major strategy factors, according SWOT Analysis, reported in Table 2.

Table 2. SWOT factors.

\begin{tabular}{|l|l|}
\hline Strengths & Opportunities \\
\hline S1. Supports national, European legislation & O1. Strong support from citizens \\
S2. Widespread applicability & O2. Creates the opportunity for green job creation \\
S2. Can have significant impact source reduction & (directly and indirectly) \\
S3. Increases life-span of landfills & \\
S4. No permits required & \\
S5. Cost-benefit interest for stakeholders & \\
S6. Benefit for citizens & Threats \\
\hline Weaknesses & T1. Low awareness of population (if not properly \\
\hline W1. When implemented at large-scale local level & \\
\hline
\end{tabular}


requires good planning to take all factors at household informed especially initially may not bad results) level into account.

W2. There is a cost (although small)

W3. Requires very good public awareness and support to citizens

\subsection{TOWS Matrix}

A next step of analysis, was associated with the identification of strategic alternatives. Thus, the SWOT factors and EPEAT parameters were used to develop the Threats-Opportunities-Weaknesses-Strengths (TOWS) Matrix or the so called the Strategic Alternatives Matrix. TOWS matrix provides means to develop strategies based on logical combinations of factors relate to internal strengths (or weaknesses) with factors related to external opportunities (or threats). In other words TOWS Matrix, helps to think about the options that you could pursue. To do this you match external opportunities and threats with your internal strengths and weaknesses, as illustrated in the matrix below reported in Table 3. The primary advantage of this approach is the influence of prioritized internal and external factors embedded in alternative strategies useful to express judgment in evaluating pairwise comparison (parag. 4.5).

Table 3.Town Matrix.

Opportunities

O1. Strong support from citizens

O2. Creates the opportunity for green job creation (directly and indirectly)

Threats

T1. Low awareness of population (if not properly informed especially initially may not bad results)

\begin{tabular}{|l|l|}
\hline Strengths & Weaknesses \\
\hline $\begin{array}{l}\text { S1. Supports national, European } \\
\text { legislation }\end{array}$ & $\begin{array}{l}\text { W1. When implemented at } \\
\text { large-scale local level requires } \\
\text { S2. Widespread applicability }\end{array}$ \\
$\begin{array}{l}\text { S2. Can have significant impact source } \\
\text { reduction }\end{array}$ & $\begin{array}{l}\text { at household level into account. } \\
\text { W2. There is a cost (although } \\
\text { S3. Increases life-span of landfills } \\
\text { S4. No permits required }\end{array}$ \\
$\begin{array}{l}\text { S5. Cost-benefit interest for stakeholders } \\
\text { S6. Benefit for citizens }\end{array}$ & $\begin{array}{l}\text { W3. Requires very good public } \\
\text { awareness and support to } \\
\text { citizens }\end{array}$ \\
C1 Strategy & W-O Strategy \\
environmentally sensitive materials & C2 Materials selection \\
C7 Corporate performance & C3 Design for end of life \\
S-T Strategy & W-T Strategy \\
C4 Product longevity/life cycle extension & C5 Energy conservation \\
& C6 End of life management \\
& C8 Packaging \\
\hline
\end{tabular}

\subsection{Definition of the model}

In this stage we defined our AHP model according the parameters described above. In details the goal of our model is the identification of "A sustainable decision making model based on AHP and SWOT Analysis" in order to improve the management of WEEE. The first level of hierarchy consists in the four criteria: Strengths, Weaknesses, Opportunities and Threats. The second level of the hierarchy consists in the 8 criteria established from EPEAT standard. The third level consists in the 23 subcriteria established from EPEAT standard. As alternatives we considered the top five laptop in Italian market. In Table 4 is shown the most important features.

Table 4.The top 5 laptop.

\begin{tabular}{|c|c|c|c|c|c|}
\hline $\mathbf{N}^{\circ}$ & Model & Processor & GB & Battery & Weight \\
\hline 1 & AM & i5 dual core & 4 GB & 7 hours & $1,10 \mathrm{~kg}$ \\
\hline 2 & LT & Intel Pentium Dual Core & 4 GB & 6 hours & $1,33 \mathrm{~kg}$ \\
\hline
\end{tabular}




\begin{tabular}{|c|c|c|c|c|c|}
\hline 3 & DX & i7 & 4 GB & 7 hours & $1,33 \mathrm{~kg}$ \\
\hline 4 & HE & i5 dual core & $4 \mathrm{~GB}$ & 7 hours & $1,33 \mathrm{~kg}$ \\
\hline 5 & SV & i7 & $4 \mathrm{~GB}$ & 8 hours & $1,50 \mathrm{~kg}$ \\
\hline
\end{tabular}

In figure 2 is shown the hierarchical structure proposed in the study and an example of relationships and influences among the parameters. All relationships among the elements are shown in Table 5.

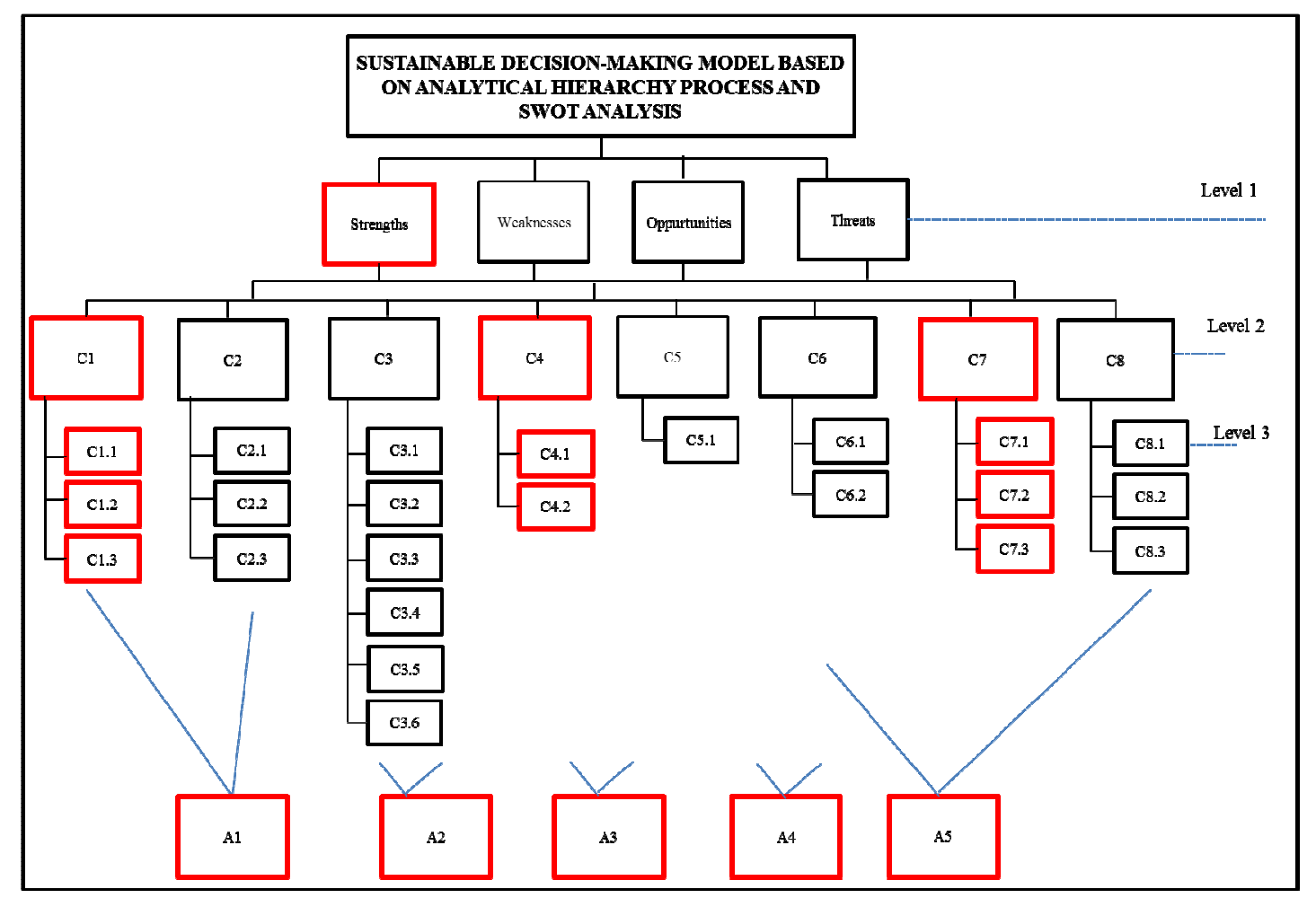

Figure 2. AHP Model.

The group of experts identified the relationships and influences among the parameters. In detail, the influences among criteria and sub-criteria were built up based on the relationships shown in Town Matrix.

Table 5. Relationships among the elements.

\begin{tabular}{|c|c|c|c|c|c|c|c|c|c|c|c|c|c|c|c|c|c|}
\hline & $\mathbf{S}$ & $\mathbf{O}$ & $\mathbf{W}$ & $\mathbf{T}$ & $\mathbf{A}$ & & $\mathbf{S}$ & $\mathbf{O}$ & $\mathbf{W}$ & $\mathbf{T}$ & $\mathbf{A}$ & & $\mathbf{S}$ & $\mathbf{O}$ & $\mathbf{W}$ & $\mathbf{T}$ & $\mathbf{A}$ \\
\hline C1.1 & 1 & 1 & 0 & 0 & 1 & C3.3 & 0 & 1 & 1 & 0 & 1 & C6.2 & 0 & 0 & 1 & 1 & 1 \\
\hline C1.2 & 1 & 1 & 0 & 0 & 1 & C3.4 & 0 & 1 & 1 & 0 & 1 & C7.1 & 1 & 1 & 0 & 0 & 1 \\
\hline C1.3 & 1 & 1 & 0 & 0 & 1 & C3.5 & 0 & 1 & 1 & 0 & 1 & C7.2 & 1 & 1 & 0 & 0 & 1 \\
\hline C2.1 & 0 & 1 & 1 & 0 & 1 & C3.6 & 0 & 1 & 1 & 0 & 1 & C7.3 & 1 & 1 & 0 & 0 & 1 \\
\hline C2.2 & 0 & 1 & 1 & 0 & 1 & C4.1 & 1 & 0 & 0 & 1 & 1 & C8.1 & 0 & 0 & 1 & 1 & 1 \\
\hline C2.3 & 0 & 1 & 1 & 0 & 1 & C4.2 & 1 & 0 & 0 & 1 & 1 & C8.2 & 0 & 0 & 1 & 1 & 1 \\
\hline $\begin{array}{l}\text { C3.1 } \\
\end{array}$ & 0 & 1 & 1 & 0 & 1 & C5.1 & 0 & 0 & 1 & 1 & 1 & C8.3 & 0 & 0 & 1 & 1 & 1 \\
\hline C3.2 & 0 & 1 & 1 & 0 & 1 & C6.1 & 0 & 0 & 1 & 1 & 1 & & & & & & \\
\hline
\end{tabular}

\subsection{Evaluating Pairwise comparison}

Pairwise comparisons of the elements in each level are conducted with respect to their relative importance towards their control criterion. Saaty suggested a scale of 1-9 when comparing two components. For 
example, number 9 represents extreme importance over another element. And number 8 represents it is between "very strong important" and "extreme importance" over another element. The result of the comparison is the so-called dominance coefficient $a_{\mathrm{ij}}$ that represents the relative importance of the component on row (i) over the component on column (j), i.e., $\mathrm{a}_{\mathrm{ij}}=w_{i} / w_{\mathrm{j}}$. The pairwise comparisons can be represented in the form of a matrix. The score of 1 represents equal importance of two components and 9 represents extreme importance of the component $i$ over the component $j$. After all pairwise comparison is completed, the priority weight vector $(w)$ is computed as the unique solution of $A w=\lambda_{\max } w$, where $\lambda_{\max }$ is the largest eigenvalue of matrix A. Saaty (1990) proposed utilizing consistency index (CI) to verify the consistency of the comparison matrix. The consistency index (CI) of the derived weights could then be calculated by: $C I=\left(\lambda_{\max }-n\right) / n-1$. In general, if CI is less than 0.10 , satisfaction of judgments may be derived.

\subsection{Evaluating results}

The data obtained were analyzed to derive factor priority and overall priority scores. In Table 5 are shown priorities for the first and second level. As we can note the most important factor is Strengths with a score of 0.454 . While the most important criteria is C7 (0.230).

Table 5.Priority. - Level 1 and Level 2

\begin{tabular}{|l|l|l|}
\cline { 2 - 3 } \multicolumn{1}{c|}{} & Strengths & Weaknesses \\
\cline { 2 - 3 } \multicolumn{1}{c|}{} & 0.454 & 0.183 \\
\hline Opportunities & S-O Strategy & W-O Strategy \\
\hline 0.218 & C1 0.210 & C2 0.110 \\
& C7 0.230 & C3 0.100 \\
\hline Threats & S-T Strategy & W-T Strategy \\
\hline 0.145 & C4 0.150 & C5 0.070 \\
& & C6 0.050 \\
& & C8 0.080 \\
\hline
\end{tabular}

The individual experts' judgments obtained through questionnaires were aggregated using the geometric mean. The global results show (Figure 3) that according to the experts best alternative with a priority score of 0.267 is A1. The second best alternative is A2 (0.242), followed by A4 (0.225) and A5 (0.144). The last is A3 with a score of 0.115 .

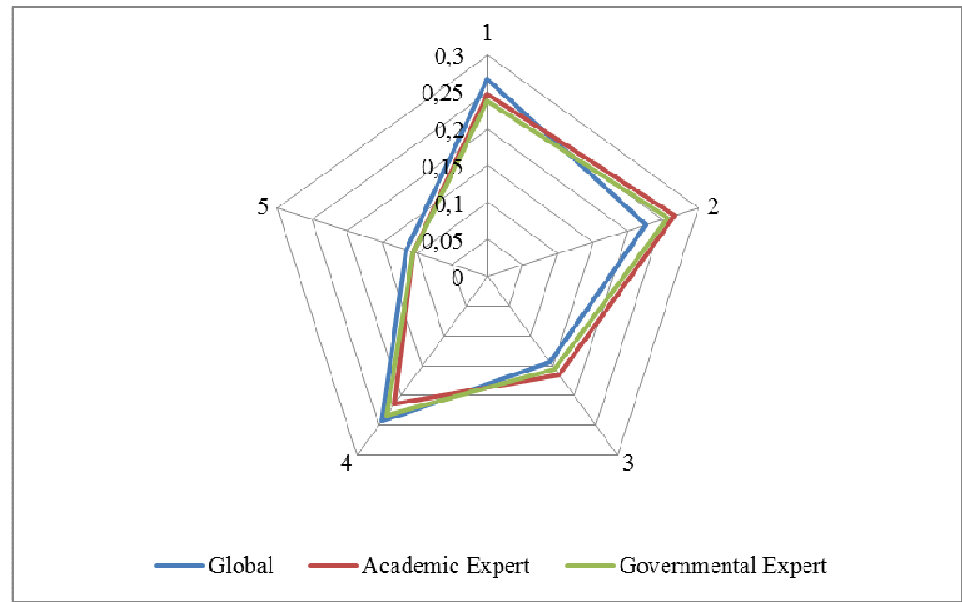

Figure 3. Global Results. 
According to the best alternative A1, we would like to note that C1.1. - Compliance with provisions of European RoHS Directive - is 0.432. The factor C1.2 - Reporting on amount of mercury used in light sources $(\mathrm{mg})$ - is 0.335 . Finally C1.3 - Elimination of intentionally added SCCP - is 0.224 . The other scores were obtained similarly. According to the previous results we can affirm that the proposed approach is useful to choose the best product in terms of environmental impacts, monitor the sustainable performance and to assess the priority of possible interventions to be taken, in order to increase the sustainability of the integrated system.

\section{Conclusions}

The present paper illustrates the development of a sustainable decision making model based on the SWOT and AHP technique with the aim of studying the improvement of End-Of-Life of WEEE.

In particular in this study, we sought to demonstrate, with a case study, that it is possible to perform a quantitative S-AHP analysis wherein the possible dependencies among SWOT factors are included. The model has not been analyzed using past data, due to the unavailability of past data for the particular management case under study. However, there are still a number of opportunities for expanding the study and for validating the obtained results. The advantages of AHP include its ability to make both qualitative and quantitative decision attributes commensurable, and its flexibility with regard to the setting of objectives. AHP is easy to apply and understand, and thus, the reformulation of the decision problem and repeating of comparisons can be profitable and educational. The idea in utilizing AHP within a SWOT framework is to systematically evaluate SWOT factors and commensurate their intensities. The hybrid method of AHP and SWOT increases and improves the information basis of strategic planning processes. The reason for discussing the strategic environments for WEEE is to promote the achievements of R\&D and the technological innovation activities.

\section{REFERENCES}

Ananda, J., \& Herath, G. (2003). The use of Analytic Hierarchy Process to incorporate stakeholder preferences into regional forest planning. Forest Policy and Economics, 5: 13-26.

Bhat, V., Rao, P., \& Patil, Y. (2012). Development of an integrated model to recover precious metals from electronic scrap - A novel strategy for e-waste management. International Conference on Emerging Economies - Prospects and Challenges (ICEE-2012).

De Felice, F., \& Petrillo, A., (2012). Green Policy in a Manufacturing System. The $2^{\text {nd }}$ International Conference on Communications, Computing and Control Applications (CCCA'12). December 6-8, 2012 at Marseilles, France.

Kajanus, M., Kangas, J., \& Kurttila, M. (2004). The use of value focused thinking and the A'WOT hybrid method in tourism management. Tourism Management, 25 (2004) 499-506.

Kumar, V., Bee, D.J., Shirodkar, P.S., Tumkor, S., Bettig, B.P., \& Sutherland, J.W. (2005). Towards sustainable product and material flow cycles: identifying barriers to achieving product multi-use and zero waste. In: Proceedings of IMECE 2005. 2005 ASME international mechanical engineering congress and exposition; 2005.

Kurttila, M., Pesonen, M., Kangas, J., \& Kajanus, M., (2000). Utilizing the analytic hierarchy process AHP in SWOT analysis - a hybrid method and its application to a forest-certification case. Forest Policy and Economics, 1: 41-52. 
Nnoroma, I.C., \& Osibanjo, O. (2008). Overview of electronic waste (e-waste) management practices and legislations, and their poor applications in the developing countries. Resources, Conservation and Recycling, 52, 843-858.

Ostrega, A., De Felice, F., \& Petrillo, A. (2011). ANP - SWOT approach to minimize environmental impacts due mining activities. Proceedings of the $11^{\text {th }}$ International Symposium on the Analytic Hierarchy Process (ISAHP). Sorrento (NA - ITALY), 15 - 18 June, 2011.

Osuna, E.E., \& Aranda, A. (2007). Combining SWOT and AHP techniques for strategic planning. Proceedings of the $9 t^{h}$ International Symposium on the Analytic Hierarchy Process (ISAHP), Viña del Mar, Chile, August 2-6, 2007.

Pesonen, M., Kurttila, M., Kangas, J., Kajanus, M., \& Heinonen, P., (2000). Assessing the priorities using A_WOT? among resource management strategies at the Finish Forest and Park Service. Forest Science, 47 (4), 534-541.

Saaty, T. L. (1990). How to make a decision: The analytic hierarchy process. European Journal of Operations Research, 48, 9-26.

Saaty, T.L., \& Vargas, L.G., (2001). Models, Methods, Concepts and Applications of the Analytic Hierarchy Process. Kluwer Academic Publishers, Boston, MA.

Schmoldt, D.L., \& Peterson, D., (2000). Analytical group decision making in natural resources: methodology and application. Forest Science, 46: 62-75.

Shinno, H., Yoshioka, H., Marpaung, S., \& Hachiga, S., (2006). Quantitative SWOT analysis on global competitiveness of machine tool industry. Journal of Engineering Design, 17 (3), 251-258.

Shrestha, R.K., Alavalapati, J.R.R., \& Kalmbacher, R.S. (2004). Exploring the potential for silvopasture adoption in South-central Florida: an application of SWOT-AHP method. Agricultural Systems, 81, 185199.

Silvestri, A., De Felice, F., \& Petrillo, A. (2012). Multi-criteria risk analysis to improve safety in manufacturing systems. International Journal of Production Research. Vol. 50, No. 17, pp. 4806-4822, 1 September 2012, 4735-4737. ISSN 0020-7543 print/ISSN 1366-588X online.

Srivastava, P.K., Kulshreshtha, K., Mohanty, C.S., Pushpangadan, P., \& Singh, A. (2005). Singh Stakeholder-based SWOT analysis for successful municipal solid waste management in Lucknow, India Waste Management, 25, 531-537.

UNEP (2007). United Nations Environment Programme: E-waste Assessment Manual.

UNEP (2009). Recycling from E-Waste to resources.

Wickramasinghe, V., \& Takano, S. (2009). Application of Combined SWOT and Analytic Hierarchy Process (AHP) for Tourism Revival Strategic Marketing Planning: A Case of Sri Lanka Tourism. Journal of the Eastern Asia Society for Transportation Studies, 8, 2009. 